\title{
Hypophysitis - new insights into diagnosis and treatment
}

\author{
Łukasz Kluczyński ${ }^{1,2}$, Aleksandra Gilis-Januszewska ${ }^{1,2}$, Damian Rogoziński ${ }^{1}$, Jacek Pantofliński', \\ Alicja Hubalewska-Dydejczyk ${ }^{1,2}$
}

${ }^{1}$ Department of Endocrinology, University Hospital in Krakow, Krakow, Poland

${ }^{2}$ Chair and Department of Endocrinology, Jagiellonian University Medical College, Krakow, Poland

\begin{abstract}
Hypophysitis is a broad term used to describe conditions leading to inflammation of the pituitary gland and the pituitary stalk. It may develop as a primary condition or secondary to other diseases. Hypophysitis is classified based on aetiological, anatomical, and histological criteria. Clinical symptoms result from enlargement of the pituitary gland, hormonal deficiencies, diabetes insipidus, and hyperprolactinemia. Histopathological verification of tissue samples from a pituitary biopsy remains the gold standard in diagnosing hypophysitis. However, due to the invasiveness and risk of the procedure it is rarely performed. The diagnosis is based mainly on clinical presentation, laboratory tests, and imaging. The rarity of the disease and the deficit in reliable data result in a lack of clear guidelines in the treatment of hypophysitis. The basic therapy relies on hormonal replacement. High doses of steroids are the first-line treatment of symptoms caused by mass effect in sella and compression of surrounding structures. In steroid-resistant patients or in cases of inacceptable sides effects, treatment with other immunosuppressant drugs was administered with success. The course of the disease varies: some patients present remission, in other cases hypophysitis leads to fibrosis and atrophy of the pituitary gland, which is reflected in persistent hormonal deficiencies and images of an empty sella. The objective of this article is to present the most important information: the epidemiology, clinical image, diagnostic procedures, and treatment of primary hypophysitis,

in order to allow better understanding of this disease and implementation of proper management. Posttraumatic and immunotherapyrelated hypophysitis are also briefly characterised. (Endokrynol Pol 2019; 70 (3): 260-269)
\end{abstract}

Key words: hypophysitis; pituitary insufficiency; hypopituitarism; diabetes insipidus; pituitary stalk lesion

\section{Introduction}

Hypophysitis is a broad term used to describe conditions leading to inflammation of the pituitary gland and the pituitary stalk. Hypophysitis may develop as a primary condition or secondary to other causes such as systemic diseases, drugs, or pathologies located near the sella turcica. Despite being a rare condition, progress in radiology studies, enhanced understanding of endocrinology, and new variants (IgG4- and immunotherapy-related) being discovered, interest in this disease is increasing. The first scientific works concerning hypopituitarism caused by infective factors were published at the beginning of the 20th century [1,2], but research about the primary pituitary pathologies leading to its insufficiency started just under 50 years ago.

\section{Classification}

Hypophysitis may be classified based on aetiological, anatomical, and histological criteria. Aetiologically, we distinguish primary inflammation - limited to the pituitary gland - as one occurring without a traceable triggering factor. Secondary hypophysitis may be related to infectious (tuberculosis, syphilis) and systemic (sarcoidosis, Crohn's disease, Langerhans cell histiocytosis) diseases, therapeutic drugs (interferon, interleukin-2, CTLA-4, and PD-1 inhibitors) or tumours in the area of sella turcica (pituitary adenomas, craniopharyngiomas, germinomas). Different parts of the pituitary gland can be subject to the disease. Specifically, inflammation of the anterior pituitary lobe (lymphocytic adenohypophysitis), the posterior pituitary lobe and stalk (lymphocytic infundibuloneurohypophysitis) or the entire pituitary gland (lymphocytic panhypophysitis) are characterised by a prevalence of 65,10 , and $25 \%$, respectively $[3,4]$. Histological classification includes lymphocytic, granulomatous, xanthomatous, IgG4-related (plasmacytic), and necrotising hypophysitis [3]. Sporadically mixed variants have also been identified, but some authors regard them as diseases with different expressions [5]. 


\section{Epidemiology}

Hypophysitis is a rare disease. The original annual incidence estimated at approximately one case per 9 million [6] seems to be an underestimation, at least due to increasing diagnosis of IgG4-related pituitary inflammation [3]. Hypophysitis is considered to cause approximately $0.4 \%(0.24-0.88 \%)$ of the neurosurgical interventions within the pituitary gland $[3,7]$. The condition is accompanied in $8-20 \%$ of cases by other autoimmune diseases, amongst which Hashimoto's and Graves-Basedow thyroiditis are the most common [3, 8-10]. Hypophysitis may be a part of autoimmune polyglandular syndrome, in particular type $3 \mathrm{~A}$, but also type 1 [11, 12]. People with HLA DR4, HLA DR5, HLA DQ8, and HLA DR53 alleles are thought to have a predisposition to be affected by primary hypophysitis $[13,14]$.

\section{Lymphocytic inflammation}

Lymphocytic inflammation is the most common histological variant of hypophysitis - $68 \%$ of cases [4]. It was described for the first time in 1962 by Goudi and Pinkerton [15]; women are more frequently affected, with a 3:1 ratio [3], typically in the fourth decade of life. Lymphocytic hypophysitis shows strong association with pregnancy (in contrast to other primary inflammations of the pituitary gland). In the majority of women, it was diagnosed in the last month of pregnancy or in puerperal period, predominantly within two months of delivery [3,16]. The aetiology is probably autoimmune.

\section{Granulomatous inflammation}

The second most common variant of hypophysitis is granulomatous inflammation, representing about $20 \%$ of diagnosed cases [4]. The first posthumous case was presented by Simmonds in 1917, and the first antemortem description was seen in 1980 $[17,18]$. The aetiology is unknown. Granulomatous inflammation affects women more often than men (3:1 ratio), mainly in the fifth decade of life. It is necessary to exclude other diseases associated with granulomas (tuberculosis, sarcoidosis, histiocytosis) prior to considering granulomatous pituitary gland inflammation as primary [19].

\section{Xanthomatous inflammation}

A rare type of hypophysitis is xanthomatous inflammation (about 3\% of cases [4]), discovered in 1998. It is believed that this variant may be an inflammatory reaction to Ratke's cleft cyst rupture [20,21]. It has been more frequently reported in women (3:1), in their fourth decade of life.

\section{Plasmocytic or IgG4-related hypophysitis}

Another type of hypophysitis is plasmocytic or IgG4-related hypophysitis. It may involve only the pituitary gland, but it may also manifest as a systemic disease, which explains why many authors consider this type as secondary. According to the majority of reports, older men are the most commonly affected patients, with a male-female ratio of 2:1. One research project showed higher prevalence among women [22]. The aetiology of this subtype is not clear, but autoimmune background and inappropriate reaction to unknown allergens or infectious factors are taken into consideration $[23,24]$. In the course of systemic disease, many organs may be involved: lymph nodes, liver, pancreas, lungs, thyroid gland, and others [24, $25,26]$; the pituitary gland is affected in $2-8 \%$ of cases [27]. Plasmocytic hypophysitis has been considered rare, but according to new research and retrospective analyses of previous doubtful cases, the prevalence is actually higher than expected [22, 28]. The criteria based on pituitary MRI, involvement of other organs, serum IGg4 level, and response to treatment allow a diagnosis to be established without a necessary pituitary gland biopsy [29].

\section{Necrotising inflammation}

The rarest type of hypophysitis is a necrotising inflammation of the pituitary gland, which was diagnosed in four patients at the ages of 12, 20, 33 , and 39 years (three cases were confirmed by a biopsy). This subtype was predominantly seen in men [30].

\section{Risk factors}

Pregnancy and childbirth are considered risk factors for primary hypophysitis [31]. According to Suzuki et al., an additional factor increasing the risk of lymphocytic adenohypophysitis is aseptic meningitis [32].

\section{Lymphocytic hypophysitis and pregnancy}

As mentioned previously, lymphocytic hypophysitis (mainly adenohypophysitis) is strongly correlated with pregnancy and the puerperal period. The occurrence of the disease does not have any adverse influence on the foetus or the course of pregnancy [3,33,34]. Previous pregnancies do not increase the risk of developing hypophysitis in subsequent pregnancies; a woman is able to become pregnant with pre-existing pituitary inflammation $[33,35,36]$. In pregnancy, the pituitary gland volume increases by about 30\% [37], mostly due to hyperplasia and hypertrophy of the lactotrophs [38], which may facilitate the release of pituitary antigens 
[39]. Moreover, due to the significant increase in oestrogen concentration, the pituitary vascularity changes and favours blood supply from the systemic circulation [40]. These modifications and the increase in tissue size explain why the immune system has a greater ability to target the pituitary gland during pregnancy. One of the factors that may connect pregnancy with hypophysitis is alpha-enolase, which was documented to be expressed in both the pituitary gland and placenta [41]. However, antibodies against this enzyme are not specific for lymphocytic inflammation because they are also present in other pituitary diseases [42]. Tumour necrosis factor (TNF) alpha is mentioned amongst potential causes of hypophysitis - its action is blocked by placenta-derived soluble TNF receptor 1 protein [43]. In contrast, a recent German retrospective analysis of 66 patients documented the relationship between pregnancy and hypophysitis (all variants) in only $11 \%$ of cases [44]. This difference may suggest the contribution of environmental factors in the pathogenesis of primary pituitary inflammations [45].

\section{Symptoms}

The clinical image of lymphocytic hypophysitis varies - both in the case of the disease onset, which may be acute or latent, as well as its course [46]. In some patients, the inflammation develops rapidly, in others - in an insidious way $[47,48]$. The time between the first symptoms and diagnosis is markedly longer for adenohypophysitis outside of pregnancy (median 12 months) than during pregnancy (median four months) and in comparison with infundibuloneurohypophysitis (median three months) and panhypophysitis (median four months) [3]. Furthermore, based on pathologies found in posthumous examination in patients without symptoms during their life, we may suspect an asymptomatic course of the disease in some cases [13,49].

Clinical symptoms may be classified in four categories: connected with enlargement of pituitary gland, hormonal deficiencies, diabetes insipidus, and hyperprolactinaemia.

Headaches and visual disturbances are the first and most common manifestations of hypophysitis. Headaches with concomitant nausea and vomiting are thought to be an effect of pituitary size increase, which causes deformation of the dura mater and the diaphragma sellae. Levy et al. proved in their work that there is no correlation between the pituitary gland volume and the severity, frequency, or duration of headaches, which suggests that there are additional causes of symptoms apart from mass effect [50]. Visual disturbances, including defects in vision field, deterioration in acuity of vision, and colour perception, arise from the compression of optic chiasm. Diplopia is rarely reported - only in patients with expansion of the enlarged pituitary gland into cavernous sinuses and those with compression of the oculomotor nerves [51-54]. Weight gain was observed in $18 \%$ of patients in a German study [44]. An unusual complication of hypophysitis is internal carotid artery occlusion [55]. Cases of pituitary apoplexy in the course of hypophysitis accompanied by severe neurological symptoms have also been reported [56, 57].

Deficit in the hormones of the anterior pituitary lobe may be a consequence of inflammatory infiltration or compression of the pituitary gland or/and hypothalamus $[46,58]$. Contrary to other causes of pituitary insufficiency, hypophysitis is characterised by frequent disturbances in ACTH and TSH secretion, which is associated with a risk of life-threatening adrenal crisis [4]. Recent research underlines a common presentation of gonadotropin deficiency $[44,59]$. Decreased growth hormone production is the rarest abnormality. The possibility of a single pituitary hormone deficiency is a typical feature of hypophysitis - most often it applies to ACTH $[48,60]$. Secondary adrenal insufficiency may have a particularly severe course in cases of a concomitant deficiency in vasopressin (ADH) because, in physiological conditions, ADH expresses a synergistic effect with CRH on ACTH release [13]. In rare situations, a severe and rapid case of adrenal cortex insufficiency may lead to sudden death [3, 13, 31, 58]. Because there is usually no correlation between radiological imaging and the degree of hormonal deficits [61, 62], one can conclude that autoimmune processes affect pituitary secreting cells and lead to subsequent endocrine disturbances [63, 64].

In hypophysitis, the prolactin level may be normal, increased, or decreased $[13,16]$. Hyperprolactinaemia has a multifactorial background - compression of a pituitary stalk, modification of dopamine receptor activity, lactotroph hypertrophy, and infiltration of secretory cells with lymphocytes, which lead to subsequent damage and release of prolactin into the circulation. There is also a hypothetical possibility of the presence of antibodies stimulating production and secretion of prolactin $[3,13]$. Hyperprolactinaemia causes menstrual irregularities, galactorrhoea, decreased libido [65, 66], and osteoporosis in the long run [67]. Persistent elevated prolactin level may favour protraction of hypophysitis due to its proinflammatory effect [68].

Diabetes insipidus (DI) occurs in approximately $35 \%$ of patients with lymphocytic hypophysitis [4]. It results from the compression of the posterior pituitary lobe and/or the stalk or due to a direct autoimmune reaction. DI may be present also in adenohypophysitis, which is explained by inhibi- 
tion of axonal anti-diuretic hormone transport caused by swollen pars tuberalis [69]. The concomitant deficit in glucocorticoids, which normally inhibit the secretion of vasopressin and aquaporin-2, masksing the DI symptoms [69-71].

Granulomatous hypophysitis is characterised by more severe symptoms. Hunn et al. determined the prevalence of headaches, visual disturbances, polydipsia/polyuria, and cranial nerve palsies in 61, 40, 27, and $27 \%$ of cases, respectively; panhypopituitarism was diagnosed in $49 \%$ and DI in $27 \%$ of cases [19]. A few sources have reported relatively frequent occurrence of nausea, vomiting, and meningeal signs [58].

Due to the low prevalence of xanthomatous and plasmocytic, hypophysitis data about the course of these variants is scarce. Based on described cases, Gutenberg et al. stated that xanthomatous hypophysitis did not cause optic chiasm compression, and it is associated with lower risk of DI as well as fewer hormonal disturbances (GH and FSH/LH deficits more frequent than ACTH and TSH deficiencies) [72]. IgG4-related pituitary inflammation involves the pituitary gland and the stalk in $65 \%$ of cases, causing panhypopituitarism in $50 \%$, anterior pituitary lobe dysfunction in $25 \%$, and DI in $18 \%$ of cases [73].

\section{Primary hypophysitis in children}

Primary hypophysitis occurs rarely in children and is characterised by a different course. The most common manifestation is DI - present in $85 \%$ of cases. The prevalence of growth hormone deficit was estimated in $76 \%$ of cases, but deficiencies of gonadotropins, TSH, and ACTH are rarer [74]. Headaches and problems with sight are present in $17 \%$ and $8 \%$, respectively. Due to the similarity of symptoms (DI and growth inhibition) tumours like germinoma, craniopharyngioma, or Langerhans cell histiocytosis should be taken into consideration in the differential diagnosis [75]. Children with suspicion of hypophysitis have a greater risk of germinoma and require careful monitoring [74, 75]. Germinomas may be also the cause of secondary pituitary gland inflammation.

\section{Diagnostics}

Histopathological verification of tissue samples from a pituitary biopsy remains the gold standard in diagnosing hypophysitis. However, due to the invasiveness and risk of the procedure, it is rarely performed. Histological aspects of primary pituitary inflammations were widely described in numerous works [3, 4, 19, 29, 47, 76-78] and are not discussed in this article. The diagnosis is based mainly on clinical presentation, laboratory tests, and imaging.

\section{Laboratory tests}

Full hormonal assessment with measurements of ACTH, morning cortisol, GH, IGF-1, oestradiol (in premenopausal women), testosterone (in men), LH, FSH, TSH, fT4, PRL, urine/plasma osmolality, sodium, and potassium concentration should be performed. At the time of diagnosis of lymphocytic hypophysitis, ACTH deficit was found in $60 \%$ of cases, $\mathrm{FSH} / \mathrm{LH}$ in $55 \%$, TSH in $52 \%, \mathrm{ADH}$ in $39 \%, \mathrm{GH}$ in $38 \%$, hyperprolactinaemia in $37 \%$, and hyperprolactinaemia in $26 \%$ of cases [4]. Abnormalities in basic tests such as total blood count, inflammatory markers, and kidney and liver function parameters are an element of differential diagnostics, which is required to exclude a secondary cause of the disease [54].

\section{Imaging}

Despite significant progress in radiology, recognition of hypophysitis is still challenging. Magnetic resonance with administration of gadolinium contrast remains the gold standard of imaging. The features suggesting primary hypophysitis are a homogeneously enhanced pituitary gland, thickening of a non-deviated stalk (in $86 \%$ cases [44]), absence of signal from the posterior pituitary lobe (more common in patients with DI), and a dural tail sign [79]. It is important to notice that the posterior pituitary lobe signal is also absent in $20 \%$ of healthy people, especially in the older population [4], and the dural tail sign is not specific because it may occur in meningiomas (the most common relation) and in other intracranial pathologies [80]. Bone structures of sella turcica generally remain intact [3,9]. The changes mentioned above are expressed mostly in lymphocytic hypophysitis and may not be present in the other variants of the disease. Turcu et al. assessed a pattern of pituitary stalk lesion enhancement in MRI. They found the strongest connection between round/diamond pattern and congenital lesions. Unfortunately, apart from patients with xanthoma disseminatium (a pyramidal pattern of enhancement), no associations between characteristic MRI image and other inflammatory lesions were detected [81].

In granulomatous hypophysitis, the distention of the sellar area is frequently observed, which makes it more challenging to differentiation from tumours [58]. It should be underlined that an empty sella image may result from a long-lasting hypophysis, leading to atrophy $[47,82]$. The distinction between pituitary adenoma and hypophysitis is often difficult. To facilitate the differentiation between these two conditions, Gutenberg et al. established a scale including time relation to pregnancy, volume and symmetry of the pituitary mass, signal intensity, signal homogeneity after contrast administration, presence of posterior pituitary 
bright spot, stalk size, and mucosal swelling. The result is measured between -13 and +8 points. A score higher than 0 suggests adenoma, and equal to or lower than 0 suggests hypophysitis [83].

Patients with a suspicion of hypophysitis should have their vision field and acuity of vision checked.

\section{Immunology}

Due to the suspicion of autoimmune character of at least part of hypophysitis, many works were devoted to identifying the antigen/antigens responsible for the disease. Many different molecules like alpha-enolase [84], secretogranin II [85], PGSF1a, and PGSF2 [86] were proposed, but their role in the pathogenesis of the disease was not clearly proven. Allix et al. revealed the presence of antibodies against rabphilin-3A in $76 \%$ of patients with lymphocytic infundibuloneurohypophysitis. The antibodies are not detected in other parasellar pathologies, which may indicate that they can be used as disease biomarkers in the future $[87,88]$. The choice of the best method of assessing anti-pituitary antibodies remains controversial; however, currently the indirect immunofluorescence is thought to be the most reliable $[31,89]$. Nonetheless, due to the low antibody sensitivity - reaching $36 \%$ in lymphocytic adenohypophysitis [3] - and the presence of anti-pituitary antibodies in other autoimmune diseases (Hashimoto's disease, diabetes type 1), which reduces their specificity, these antibodies cannot be considered as a fully useful diagnostic tool. That being said, lack of antibodies against the pituitary gland does not allow for exclusion of the hypophysitis, because they may be present at the beginning of the disease and then disappear [8]. De Bellis et al. detected the presence of immunoglobulins against $\mathrm{CRH}$-producing cells in patients with a deficit in ACTH and TSH and anti-pituitary antibodies against GH, indicating potential autoimmune reaction involving the hypothalamus [90]. Assessment of antibodies against anti-diuretic hormone in patients with hypophysitis may be helpful in identifying cases with a greater risk of developing DI [91].

\section{Differential diagnosis}

Hypophysitis should be primarily differentiated from a pituitary adenomas and Sheehan syndrome (postpartum pituitary gland necrosis). In prolactinomas, which often enlarge during pregnancy, a history of menstrual disturbances and difficulty in getting pregnant $[65,66]$ is frequent. However, such abnormalities are rarely reported in hypophysitis [61]. In the case of uncertainty, magnetic resonance can be useful because in hypophysitis, stalk deviation, and destruction of sella bone structures are not observed, while adenomas may cause infundibulum displacement and erosive changes in the sellar floor [3, 92]. Postgadolinium enhancement in hypophysitis is predominantly homogenous, more intensive, and seen earlier than in adenomas, with a positive dural tail sign; lack of posterior pituitary lobe signal is common [3]. Finally, the pattern of hormonal deficits is different in adenomas, one can detect deficiencies of $\mathrm{GH}$, then $\mathrm{LF} / \mathrm{FSH}$, and subsequently TSH and ACTH, but in hypophysitis adrenal axis insufficiency is the earliest finding, followed by abnormalities of the thyroid and gonadal axes; the GH level is decreased less often [4]. Some authors suggest that a test with dopamine agonists be performed in the case of doubt in differentiation between hypophysitis and prolactinoma - in the latter, a reduction of tumour size is usually detected, an effect that is not observed in inflammation of the pituitary gland, despite the decrease in prolactin concentration [24]. The common characteristic of hypophysitis and Sheehan syndrome is that they are often seen in the puerperal period $[61,93]$. The first symptoms of hypophysitis are preponderantly present in late pregnancy, while Sheehan syndrome is associated with consequences of traumatic course of childbirth with haemodynamic complications. The classic presentation of postpartum necrosis of the pituitary gland is absent lactation, which is quite uncommon in lymphocytic pituitary inflammation [93]. In both conditions, the development of symptoms of empty sella syndrome with multiple hormonal deficiencies may occur in the long run $[61,93]$. Distinction between postpartum pituitary gland necrosis and hypophysitis is not always possible - ischaemia in the course of Sheehan syndrome may elicit an autoimmune reaction leading to persistent hypopituitarism [94].

\section{Treatment}

The rarity of the disease and the deficit in reliable data result in a lack of clear guidelines in the treatment of hypophysitis. The basic therapy relies on hormonal replacement $[95,96]$ in accordance with standard treatment of hypopituitarism and DI. Administration of adrenal hormone substitution should precede implementation of levothyroxine. Inhibiting pituitary hormone production with a subsequent reduction in hypothetical pituitary antigen expression after treatment initiation may stop or impede the progression of the disease [8]. If the symptoms are not severe and are not increasing, further careful observation is possible [44,97]. This does not apply to IgG-4-related hypophysitis - in which case steroids are advised in order to reduce symptoms and prevent fibrosis [98]. The starting dose is $30-40 \mathrm{mg}$ of prednisone or equivalent, with subsequent reduction [26]. Some patients benefit from long-term therapy. Due 
to the possibility of recurrences, some cases require repeated cycles of steroids [4]. Treatment with rituximab or azathioprine may be used in patients with poor response to glucocorticoids $[26,99]$. High doses of steroids are the first-line treatment in symptoms caused by mass effect in the sella and compression of surrounding structures. In steroid-resistant patients or in the case of inacceptable sides effects, treatment with azathioprine, methotrexate, rituximab, and cyclosporine A was administered with success $[45,100]$. However, long-term observation of patients on these therapies is still absent. Due to reports about immunomodulatory prolactin action, some authors advocate the use of dopamine agonists in order to initiate the response for treatment $[68,101]$, but the efficacy of this method is uncertain [45]. Bromocriptine or cabergoline may help to reduce symptoms resulting from hyperprolactinaemia and decrease vision field deficits [58].

Surgical treatment - the historical treatment of choice [3] — is currently reserved for patients with severe deficits in their vision fields, impaired vision acuity, and oculomotor nerve palsies, as well as those who are resistant to pharmacological treatment. The advantage of invasive methods is the possibility of histopathological assessment of material taken during surgery, which allows a final diagnosis to be made. However, the drawbacks include the risk of complications: deterioration in vision, development of diabetes insipidus, worsening of pituitary dysfunction [48,57], bleeding, or even causing cerebrospinal fluid leakage [3].

Radiotherapy is an option for patients in whom other methods appeared to be unsuccessful or those with recurrent disease.

\section{Prognosis}

Little is known about the natural history of hypophysitis, and the majority of the information concerns the lymphocytic variant. Prognostic factors include the degree of pituitary infiltration, severity of fibrosis, presence of symptoms resulting from compression, and steroid susceptibility [102]. The disease may have a self-limiting course $[44,47,97]$. According to a recent German study, MRI changes in patients without any active treatment revealed improvement, stabilisation, or deterioration in pituitary involvement in 46,27 , and $27 \%$ of cases, respectively. Hormonal function improved in $27 \%$ and remained unchanged in 55\%; $18 \%$ of patients experienced progression [44]. Previously, Khare et al. documented spontaneous resolution of sella turcica compression in all observed patients, with at least partial improvement in pituitary function in 33\% of them [97].

In patients qualified for therapy with high-dose steroids, the improvement of hormonal function was observed only in $15 \%$ of cases; in $70 \%$ it remained stable, while $15 \%$ of patients presented progression. Good response with radiological improvement, stabilisation, or deterioration was found in 65,31 , and $4 \%$ of cases, respectively [44]. More than $70 \%$ of patients required long-term substitution with one or more anterior pituitary hormones [3]. Diabetes insipidus is usually persistent. The risk of relapse is estimated at about $38 \%$, independently of initial drug dose and duration of the therapy [44]. Recurrence occurs commonly within 2-17 months from the beginning of treatment. A literature review made by Lupi et al. presented more optimistic results: reduction in pituitary size in $88 \%$ of cases, improvement in anterior and posterior pituitary lobe function in $45 \%$ and $41 \%$, respectively, with low risk of relapse - 14\% [103]. The occurrence of diabetes insipidus is an unfavourable factor in the context of response to glucocorticoids [104]. Lack of sensitivity to steroids and frequent, severe side-effects limit this method of treatment.

Steroid therapy brings much worse effects in the treatment of granulomatous and xanthomatous hypophysitis [72].

Surgical treatment leads to significant improvement in headaches and visual disturbances [44, 72]. Relapses are described in $11-25 \%$ of cases [44]. Postoperative observations show a large number of patients with pituitary insufficiency [54].

In its course, hypophysitis frequently leads to fibrosis and atrophy of the pituitary gland, which is reflected in hormonal deficiencies and images of an empty sella.

Hypophysitis-related mortality was estimated to be about $7 \%$ of cases, which is probably an effect of unrecognised adrenal cortex insufficiency [4].

\section{Immunotherapy-related hypophysitis}

Checkpoint inhibitors are monoclonal antibodies used in oncological therapies; their role is to inhibit the regulators of autoimmune responses [4]. Hypophysitis may be one of their side-effects, and it is seen in $0-17 \%$ of patients treated with anti-CTLA-4 antibody $[105,106]$ and in less than $1 \%$ of patients treated with anti-PD1 or anti-PD-L1 antibodies [107]. The symptoms appear most frequently after 2-3 months of therapy (on average - nine weeks) [108]. Male sex (4:1 ratio) and older age (average age of diagnosis -59 years) are reported among the most common risk factors $[4,89,109]$. The potential mechanism of inflammation is based on type II and IV hypersensitivity and on humoral response, with the production of anti-pituitary antibodies targeted mainly TSH, FSH, and ACTH-secreting cells [4, $110-112]$. Patients present with headaches and symp- 
toms resulting from anterior pituitary lobe hormone deficiencies, which are seen in over $70 \%$ of cases; the adrenal, thyroid, and gonadal axes are affected in about 91,84 , and $83 \%$ of patients, respectively [100]. A decrease in TSH concentration may be an early sign of developing hypophysitis [113]. Reliable data about somatotrophic axis dysfunction is missing. In sporadic cases, hyponatraemia was also observed [114]. Diabetes insipidus is extremely rare, which distinguishes immunotherapy-related hypophysitis from other forms of pituitary inflammations [105, 115]. Up to $45 \%$ of patients may be asymptomatic but present with abnormal laboratory findings [116]. Normal size or moderate enlargement of the pituitary gland (in about $50 \%$ of patients it precedes the occurrence of clinical symptoms [109]), usually without optic chiasm compression, is observed in imaging. The diagnosis is based on clinical presentation, results of laboratory tests, and imaging as well as short period of time elapsing from the exposure to immunotherapy [109, 115]. Pituitary hormone substitution and steroids in high doses are used in therapy. The decision about continuation or cessation (transient or persistent) of immunotherapy should be based on the degree of severity of symptoms and requires close cooperation of an oncologist and endocrinologist. Normalisation in the radiological image is most likely to be observed within two months [115]. Restoration of function of gonadal and thyroid axes is obtained quite commonly; the adrenal axis usually requires long-term substitution $[89,116,117]$. An additional issue is the ability to differentiate between immunotherapy-related hypophysitis and metastasis to the pituitary gland [109, 117]. An important distinguishing factor is diabetes insipidus, rarely seen in checkpoint-inhibitor related hypophysitis but common (in about $45 \%$ ) in the case of a mass in the pituitary gland [4].

\section{Traumatic brain injury}

Traumatic brain injury (TBI) may lead to permanent or transient pituitary insufficiency. The pathophysiology of the hypopituitarism after TBI is not fully understood. Apart from the direct effects of trauma and vascular damage, an interaction between the TBI and autoimmunity has been indicated. Anti-pituitary and anti-hypothalamic antibodies could be present in patients with pituitary disorders related to TBI even five years after diagnosis [118]. In a prospective five-year observation of patients post TBI, those with higher titres of pituitary antibodies developed pituitary insufficiency more frequently, while the recovery of pituitary function was related to the negative antibody titres $[119,120]$.

\section{Conclusions}

Despite the increasing rate of detection, the diagnosis and management of hypophysitis remains challenging. Difficulties in establishing the exact diagnosis might also be related to the non-specific, transient characteristics of the symptoms and hormonal insufficiencies. Long-term observations might help us better understand the disease. Further research is required in order to elaborate treatment algorithms and discover new disease biomarkers that could help establish an accurate diagnosis without the need to perform a biopsy.

\section{References}

1. Simmonds M. Über Hypophysischwund mit tödlichem ausgang. Dtsch Med Wochenschr. 1914; 40(7): 322-323.

2. Gliński LKZ. Z kazuistyki zmian anatomo-patologicznych w przysadce mózgowej. Prz Lek. 1913; 52: 13-14.

3. Caturegli P, Newschaffer C, Olivi A, et al. Autoimmune hypophysitis. Endocr Rev. 2005; 26(5): 599-614, doi: 10.1210/er.2004-0011, indexed in Pubmed: 15634713.

4. Prete A, Salvatori R. Hypophysitis. Endotext [Internet]. South Dartmouth 2018. https://www.ncbi.nlm.nih.gov/books/NBK519842/.

5. McKeel DW. Primary hypothyroidism and hypopituitarism in a young woman. Am J Med. 1984; 77(2): 319-330, indexed in Pubmed: 6431816.

6. Buxton N, Robertson I. Lymphocytic and granulocytic hypophysitis: a single centre experience. Br J Neurosurg. 2001; 15(3): 242-5, discussion 245, doi: 10.1080/02688690120057664, indexed in Pubmed: 11478060.

7. Sautner D, Saeger W, Lüdecke DK, et al. Hypophysitis in surgical and autoptical specimens. Acta Neuropathol. 1995; 90(6): 637-644, doi: 10.1007/s004010050380, indexed in Pubmed: 8615086.

8. De Bellis A, Bizzarro A, Bellastella A. Pituitary antibodies and lymphocytic hypophysitis. Best Pract Res Clin Endocrinol Metab. 2005; 19(1): 67-84, doi: 10.1016/j.beem.2004.11.007, indexed in Pubmed: 15826923.

9. Nakamura Y, Okada H, Wada Y, et al. Lymphocytic hypophysitis: its expanding features. J Endocrinol Invest. 2001; 24(4): 262-267, doi: 10.1007/BF03343856, indexed in Pubmed: 11383913.

10. Barbaro D, Loni G. Lymphocytic hypophysitis and autoimmune thyroid disease. J Endocrinol Invest. 2000; 23(5): 339-340, doi: 10.1007/BF03343733, indexed in Pubmed: 10882154.

11. Betterle C,Zanchetta R. Update on autoimmune polyendocrine syndromes (APS). Acta Biomed. 2003; 74(1): 9-33, indexed in Pubmed: 12817789.

12. Weetman AP. Non-thyroid autoantibodies in autoimmune thyroid disease. Best Pract Res Clin Endocrinol Metab. 2005; 19(1): 17-32, doi: 10.1016/j.beem.2004.11.004, indexed in Pubmed: 15826920 .

13. Bellastella A, Bizzarro A, Coronella C, et al. Lymphocytic hypophysitis: a rare or underestimated disease? Eur J Endocrinol. 2003; 149(5): 363-376, doi: 10.1530/eje.0.1490363, indexed in Pubmed: 14585081.

14. Heaney AP, Sumerel B, Rajalingam R, et al. HLA Markers DO8 and DR53 Are Associated With Lymphocytic Hypophysitis and May Aid in Differential Diagnosis. J Clin Endocrinol Metab. 2015; 100(11): 4092-4097, doi: 10.1210/jc.2015-2702, indexed in Pubmed: 26317559.

15. Goudie RB, Pinkerton PH, Goudie RB, et al. Anterior hypophysitis and hashimoto's disease in a young woman. J Pathol Bacteriol. 1962; 83(2): 584-585, doi: 10.1002/path.1700830241, indexed in Pubmed: 13900798.

16. Caturegli P, Lupi I, Landek-Salgado M, et al. Pituitary autoimmunity: 30 years later. Autoimmun Rev. 2008; 7(8): 631-637, doi: 10.1016/j.autrev.2008.04.016, indexed in Pubmed: 18774118.

17. Simmonds M, Simmonds M, Simmonds M. Über das Vorkommen von Riesenzellen in der Hypophyse. Virchows Archiv Path Anat Physiol Klin Med. 1917; 223(3): 281-290, doi: 10.1007/bf02034323.

18. Taylon C, Duff TA, Taylon C, et al. Giant cell granuloma involving the pituitary gland. Case report. J Neurosurg. 1980; 52(4): 584-587, doi: 10.3171/jns.1980.52.4.0584, indexed in Pubmed: 7373382.

19. Hunn BHM, Martin WG, Simpson S, et al. Idiopathic granulomatous hypophysitis: a systematic review of 82 cases in the literature. Pituitary. 2014; 17(4): 357-365, doi: 10.1007/s11102-013-0510-4, indexed in Pubmed: 23990347.

20. Kleinschmidt-DeMasters BK, Lillehei KO, Hankinson TC, et al. Review of xanthomatous lesions of the sella. Brain Pathol. 2017; 27(3): 377-395, doi: 10.1111/bpa.12498, indexed in Pubmed: 28236350

21. Duan K, Asa SL, Winer D, et al. Xanthomatous Hypophysitis Is Associated with Ruptured Rathke's Cleft Cyst. Endocr Pathol. 2017; 28(1): 83-90, doi: 10.1007/s12022-017-9471-x, indexed in Pubmed: 28120170. 
22. Bernreuther C, Illies C, Flitsch J, et al. IgG4-related hypophysitis is highly prevalent among cases of histologically confirmed hypophysitis. Brain Pathol. 2017; 27(6): 839-845, doi: 10.1111/bpa.12459, indexed in Pubmed: 27864854

23. Kuruma S, Kamisawa T, Tabata T, et al. Allergen-specific IgE Antibody Serologic Assays in Patients with Autoimmune Pancreatitis. Intern Med. 2014; 53(6): 541-543, doi: 10.2169/internalmedicine.53.0963, indexed in Pubmed: 24633022.

24. Stone JH, Zen Y, Deshpande V, et al. IgG4-related disease. N Engl J Med. 2012; 366(6): 539-551, doi: 10.1056/NEJMra1104650, indexed in Pubmed: 22316447.

25. Weindorf SC, Frederiksen JK, Weindorf SC, et al. IgG4-Related Dis ease: A Reminder for Practicing Pathologists. Arch Pathol Lab Med. 2017; 141(11): 1476-1483, doi: 10.5858/arpa.2017-0257-RA, indexed in Pubmed: 29072949.

26. Khosroshahi A, Wallace ZS, Crowe JL, et al. Second International Symposium on IgG4-Related Disease, Second International Symposium on IgG4-Related Disease, Second International Symposium on IgG4-Related Disease. International Consensus Guidance Statemen on the Management and Treatment of IgG4-Related Disease. Arthritis Rheumatol. 2015; 67(7): 1688-1699, doi: 10.1002/art.39132, indexed in Pubmed: 25809420.

27. Lin $\mathrm{W}, \mathrm{Lu} \mathrm{S}$, Chen $\mathrm{H}$, et al. Clinical characteristics of immunoglobulin G4-related disease: a prospective study of 118 Chinese patients. Rheumatology (Oxford). 2015; 54(11): 1982-1990, doi: 10.1093/rheumatology/kev203, indexed in Pubmed: 26106212.

28. Bando H, Iguchi G, Fukuoka H, et al. The prevalence of IgG4-related hypophysitis in 170 consecutive patients with hypopituitarism and/or central diabetes insipidus and review of the literature. Eur J Endocrinol. 2014; 170(2): 161-172, doi: 10.1530/EJE-13-0642, indexed in Pubmed: 24165017.

29. Leporati P, Landek-Salgado MA, Lupi I, et al. IgG4-related hypophysitis: a new addition to the hypophysitis spectrum. J Clin Endocrino Metab. 2011; 96(7): 1971-1980, doi: 10.1210/jc.2010-2970, indexed in Pubmed: 21593109.

30. Gutenberg A, Caturegli P, Metz I, et al. Necrotizing infundibulo-hypophysitis: an entity too rare to be true? Pituitary. 2012; 15(2): 202-208, doi: 10.1007/s11102-011-0307-2, indexed in Pubmed: 21479815.

31. Fukuoka H. Hypophysitis. Endocrinol Metab Clin North Am. 2015; 44(1) 143-149, doi: 10.1016/j.ecl.2014.10.011, indexed in Pubmed: 25732650.

32. Suzuki K, Izawa N, Nakamura T, et al. Lymphocytic Hypophysitis Accompanied by Aseptic Meningitis Mimics Subacute Meningoencephalitis. Intern Med. 2011; 50(18): 2025-2030, doi: 10.2169/internalmedicine.50.5386, indexed in Pubmed: 21921390.

33. Brandes JC, Cerletty JM, Brandes JC, et al. Pregnancy in lymphocytic hypophysitis: case report and review. Wis Med J. 1989; 88(11): 29-32, indexed in Pubmed: 2690469.

34. Molitch ME. Pituitary diseases in pregnancy. Semin Perinatol. 1998; 22(6): 457-470, doi: 10.1016/S0146-0005(98)80026-8, indexed in Pubmed: 9880116

35. Tsur A, Leibowitz G, Samueloff A, et al. Successful pregnancy in a patien with preexisting lymphocytic hypophysitis. Acta Obstet Gynecol Scan. 1996; 75(8): 772-774, doi: 10.3109/00016349609065747.

36. Gagneja H, Arafah B, Taylor HC, et al. Histologically proven lymphocytic hypophysitis: spontaneous resolution and subsequent pregnancy. Mayo Clin Proc. 1999; 74(2): 150-154, doi: 10.4065/74.2.150, indexed in Pubmed: 10069353

37. Gonzalez JG, Elizondo G, Saldivar D, et al. Pituitary gland growth during normal pregnancy: an in vivo study using magnetic resonance imaging. Am J Med. 1988; 85(2): 217-220, doi: 10.1016/S0002-9343(88)80346-2, indexed in Pubmed: 3400697.

38. Asa SL, Penz G, Kovacs K, et al. Prolactin cells in the human pituitary. A quantitative immunocytochemical analysis. Arch Pathol Lab Med. 1982; 106(7): 360-363, indexed in Pubmed: 7046682.

39. Pouplard-Barthelaix A, Lepinard V, Luxembourger L, et al. Circulating pituitary autoantibodies against cells secreting luteinising and follicle stimulating hormones in children with cryptorchidism. Lancet. 1984; 2(8403): 631-632, indexed in Pubmed: 6147655.

40. Elias KA, Weiner RI. Direct arterial vascularization of estrogen-induced prolactin-secreting anterior pituitary tumors. Proc Natl Acad Sci USA. 1984; 81(14): 4549-4553, doi: 10.1073/pnas.81.14.4549, indexed in Pubmed: 6589610 .

41. O'Dwyer DT, Clifton V, Hall A, et al. Pituitary autoantibodies in lymphocytic hypophysitis target both gamma- and alpha-enolase a link with pregnancy? Arch Physiol Biochem. 2002; 110(1-2): 94-98, doi: 10.1076/apab.110.1.94.897, indexed in Pubmed: 11935405.

42. Bensing S, Fetissov SO, Mulder J, et al. Pituitary autoantibodies in autoimmune polyendocrine syndrome type 1 . Proc Natl Acad Sci USA. 2007; 104(3): 949-954, doi: 10.1073/pnas.0610070104, indexed in Pubmed: 17215373.

43. Landek-Salgado MA, Rose NR, Caturegli P. Placenta suppresses experimental autoimmune hypophysitis through soluble TNF receptor
1. J Autoimmun. 2012; 38(2-3): J88-J96, doi: 10.1016/j.jaut.2011.07.001, indexed in Pubmed: 21788115.

44. Honegger J, Schlaffer S, Menzel C, et al. Pituitary Working Group of the German Society of Endocrinology, Pituitary Working Group of the German Society of Endocrinology, Pituitary Working Group of the German Society of Endocrinology. Diagnosis of Primary Hypophysitis in Germany. J Clin Endocrinol Metab. 2015; 100(10): 3841-3849, doi: 10.1210/jc.2015-2152, indexed in Pubmed: 26262437.

45. Bellastella G, Maiorino MI, Bizzarro A, et al. Revisitation of autoimmune hypophysitis: knowledge and uncertainties on pathophysiological and clinical aspects. Pituitary. 2016; 19(6): 625-642, doi: 10.1007/s11102-016-0736-z, indexed in Pubmed: 27503372.

46. Cosman F, Post K, Holub D, et al. Lymphocytic Hypophysitis. Report of 3 New Cases and Review of the Literature. Medicine. 1989; 68(4): 240 doi: 10.1097/00005792-198907000-00006, indexed in Pubmed: 2661963.

47. Beressi N, Beressi JP, Cohen R, et al. Lymphocytic hypophysitis. A review of 145 cases. Ann Med Interne (Paris). 1999; 150(4): 327-341, indexed in Pubmed: 10519020

48. Lipscombe L, Asa S, Ezzat S, et al. Management of Lesions of the Pituitary Stalk and Hypothalamus. The Endocrinologist. 2003; 13(1): 38-51, doi: 10.1097/00019616-200301000-00009.

49. Pestell RG, Best JD, Alford FP, et al. Lymphocytic hypophysitis. The clinical spectrum of the disorder and evidence for an autoimmune pathogenesis. Clin Endocrinol (Oxf). 1990; 33(4): 457-466, indexed in Pubmed: 2121396.

50. Levy MJ, Jäger HR, Powell M, et al. Pituitary volume and headache: size is not everything. Arch Neurol. 2004; 61(5): 721-725, doi: 10.1001/archneur.61.5.721, indexed in Pubmed: 15148150.

51. Supler M, Mickle J. Lymphocytic hypophysitis: report of a case in a man with cavernous sinus involvement. Surgical Neurology. 1992; 37(6): 472-476, doi: 10.1016/0090-3019(92)90138-d, indexed in Pubmed: 1595053.

52. Tubridy N, Saunders D, Thom M, et al. Infundibulohypophysitis in a man presenting with diabetes insipidus and cavernous sinus involvement. J Neurol Neurosurg Psychiatry. 2001; 71(6): 798-801, doi: 10.1136/jnnp.71.6.798, indexed in Pubmed: 11723207.

53. Kartal I, Yarman S, Tanakol R, et al. Lymphocytic panhypophysitis in a young man with involvement of the cavernous sinus and clivus. Pituitary. 2007; 10(1): 75-80, doi: 10.1007/s11102-007-0003-4, indexed in Pubmed: 17273922 .

54. Joshi MN, Whitelaw BC, Carroll PV, et al. Mechanisms in endocrinology: hypophysitis: diagnosis and treatment. Eur J Endocrinol. 2018; 179(3): R151-R163, doi: 10.1530/EJE-17-0009, indexed in Pubmed: 29880706.

55. Ikeda J, Kuratsu J, Miura M, et al. Lymphocytic adenohypophysitis accompanying occlusion of bilateral internal carotid arteries case report. Neurol Med Chir (Tokyo). 1990; 30(5): 346-349, doi: 10.2176/nmc.30.346, indexed in Pubmed: 1699152.

56. Wu GF, Balcer LJ. Endocrine and metabolic deficiency. Ophthalmol Clin North Am. 2004; 17(3): 427-34, vii, doi: 10.1016/j.ohc.2004.05.010, indexed in Pubmed: 15337197

57. Crock P. Lymphocytic hypophysitis. Curr Opin Endocrinol Diab Obes. 1997; 4(2): 115-123, doi: 10.1097/00060793-199704000-00007.

58. Cheung CC, Ezzat S, Smyth HS, et al. The spectrum and significance of primary hypophysitis. J Clin Endocrinol Metab. 2001; 86(3): 1048-1053, doi: 10.1210/jcem.86.3.7265, indexed in Pubmed: 11238484

59. Falorni A, Minarelli V, Bartoloni E, et al. Diagnosis and classification of autoimmune hypophysitis. Autoimmun Rev. 2014; 13(4-5): 412-416, doi: 10.1016/j.autrev.2014.01.021, indexed in Pubmed: 24434361.

60. Nagai Y, Ieki Y, Ohsawa K, et al. Simultaneously found transient hypothyroidism due to hashimoto's thyroiditis, autoimmune hepatitis and isolated ACTH deficiency after cessation of glucocorticoid administration. Endocrine Journal. 1997; 44(3): 453-458, doi: 10.1507/endocrj.44.453, indexed in Pubmed: 9279524.

61. Breen T, Post K, Wardlaw S. Lymphocytic hypophysitis. The Endocrinologist. 2004; 14(1): 13-18, doi: 10.1097/01.ten.0000113246.79886.1f

62. Guay AT, Agnello US, Freidberg SR, et al. Lymphocytic adenohypophysitis in a man. Can J Neurol Sci. 1988; 15(4): 439-440, indexed in Pubmed: 3208233.

63. De Bellis A, Bellastella G, Colella C, et al. Use of serum pituitary antibodies to improve the diagnosis of hypophysitis. Expert Rev Endocrino Metab. 2014; 9(5): 465-476, doi: 10.1586/17446651.2014.932689, indexed in Pubmed: 30736209

64. Hashimoto K, Takao T, Makino S. Lymphocytic adenohypophysitis and lymphocytic infundibuloneurohypophysitis. Endocr J. 1997; 44(1): 1-10, doi: 10.1507/endocrj.44.1, indexed in Pubmed: 9152609.

65. Molitch ME. Endocrine emergencies in pregnancy. Baillieres Clin Endocrinol Metab. 1992; 6(1): 167-191, doi: 10.1016/S0950-351X(05)80337-4 indexed in Pubmed: 1739393.

66. Prager D, Braunstein GD. Pituitary disorders during pregnancy. Endocrinol Metab Clin North Am. 1995; 24(1): 1-14, doi: 10.1016/S0889-8529(18)30051-3, indexed in Pubmed: 7781620.

67. Melmed S, Casanueva FF, Hoffman AR, et al. Endocrine Society, Endocrine Society. Diagnosis and treatment of hyperprolactinemia: an Endo- 
crine Society clinical practice guideline. J Clin Endocrinol Metab. 2011; 96(2): 273-288, doi: 10.1210/jc.2010-1692, indexed in Pubmed: 21296991.

68. Shelly S, Boaz M, Orbach $\mathrm{H}$, et al. Prolactin and autoimmunity. Autoimmun Rev. 2012; 11(6-7): A465-A470, doi: 10.1016/j.autrev.2011.11.009, indexed in Pubmed: 22155203.

69. De Bellis A, Bizzarro A, Perrino S, et al. Characterization of antipituitary antibodies targeting pituitary hormone-secreting cells in idiopathic growth hormone deficiency and autoimmune endocrine diseases. Clin Endocrinol (Oxf). 2005; 63(1): 45-49, doi: 10.1111/j.1365-2265.2005.0229 6.x, indexed in Pubmed: 15963060.

70. Koshiyama H, Sato H, Yorita S, et al. Lymphocytic Hypophysitis Presenting with Diabetes Insipidus: Case Report and Literature Review. Endocrine Journal. 1994; 41(1): 93-97, doi: 10.1507/endocrj.41.93, indexed in Pubmed: 7951558.

71. Ohta M, Kimura T, Ota K, et al. Glucocorticoid-Induced Central Diabetes Insipidus in a Case of Malignant Lymphoma. Tohoku J Exp Med. 1991; 163(4): 245-254 doi: 10.1620/tjem.163.245, indexed in Pubmed: 1882385.

72. Gutenberg A, Hans V, Puchner MJA, et al. Primary hypophysitis: clinical-pathological correlations. Eur J Endocrinol. 2006; 155(1): 101-107, doi: 10.1530/eje.1.02183, indexed in Pubmed: 16793955

73. Shikuma J, Kan K, Ito R, et al. Critical review of IgG4-related hypophysitis. Pituitary. 2017; 20(2): 282-291, doi: 10.1007/s11102-016-0773-7, indexed in Pubmed: 27812776.

74. Kalra AA, Riel-Romero RM, Gonzalez-Toledo E. Lymphocytic hypophysitis in children: a novel presentation and literature review. J Child Neurol. 2011; 26(1): 87-94, doi: 10.1177/0883073810373278, indexed in Pubmed: 21212455.

75. Gan, HW, Bulwer C, Spoudeas H. Pituitary and hypothalamic tumor syndromes in childhood. Endotext [Internet]. South Dartmouth 2017. https://www.ncbi.nlm.nih.gov/books/NBK279153/.

76. Fehn M, Sommer C, Ludecke DK, et al. Lymphocytic Hypophysitis: Light and Electron Microscopic Findings and Correlation to Clinical Appearance. Endocr Pathol. 1998; 9(1): 71-78, indexed in Pubmed: 12114664

77. Sautner D, Saeger W, Lüdecke DK, et al. Hypophysitis in surgical and autoptical specimens. Acta Neuropathol. 1995; 90(6): 637-644, doi: 10.1007/BF00318578, indexed in Pubmed: 8615086

78. Krysiak R, Okopień B, Herman ZS. [Hypophysitis]. Przegl Lek. 2007; 64(7-8): 515-520, indexed in Pubmed: 18409356

79. Saiwai S, Inoue $Y$, Ishihara T, et al. Lymphocytic adenohypophysitis: skull radiographs and MRI. Neuroradiology. 1998; 40(2): 114-120, doi: 10.1007/s002340050550, indexed in Pubmed: 9541922

80. Sotoudeh H, Yazdi HR. A review on dural tail sign. World J Radiol. 2010; 2(5): 188-192, doi: 10.4329/wjr.v2.i5.188, indexed in Pubmed: 21161034.

81. Turcu AF, Erickson BJ, Lin E, et al. Pituitary stalk lesions: the Mayo Clinic experience. J Clin Endocrinol Metab. 2013; 98(5): 1812-1818, doi: 10.1210/jc.2012-4171, indexed in Pubmed: 23533231.

82. Gao H, Gu YY, Qiu Mc. Autoimmune hypophysitis may eventually become empty sella. Neuro Endocrinol Lett. 2013; 34(2): 102-106, indexed in Pubmed: 23645305.

83. Gutenberg A, Larsen J, Lupi I, et al. A radiologic score to distinguish autoimmune hypophysitis from nonsecreting pituitary adenoma preoperatively. AJNR Am J Neuroradiol. 2009; 30(9): 1766-1772, doi: 10.3174/ajnr. A1714, indexed in Pubmed: 19628625.

84. Crock PA. Cytosolic autoantigens in lymphocytic hypophysitis. J Clin Endocrinol Metab. 1998; 83(2): 609-618, doi: 10.1210/jcem.83.2.4563, indexed in Pubmed: 9467582.

85. Bensing S, Hulting AL, Höög A, et al. Lymphocytic hypophysitis: report of two biopsy-proven cases and one suspected case with pituitary autoantibodies. J Endocrinol Invest. 2007; 30(2): 153-162, doi: 10.1007/BF03347415, indexed in Pubmed: 17392607.

86. Tanaka S, Tatsumi Ki, Kimura M, et al. Detection of autoantibodies against the pituitary-specific proteins in patients with lymphocytic hypophysitis. Eur J Endocrinol. 2002; 147(6): 767-775, indexed in Pubmed: 12457452.

87. Allix I, Rohmer V. Hypophysitis in 2014. Ann Endocrinol (Paris). 2015; 76(5): 585-594, doi: 10.1016/j.ando.2015.08.003, indexed in Pubmed: 26514950.

88. Iwama S, Sugimura Y, Kiyota A, et al. Rabphilin-3A as a Targeted Autoantigen in Lymphocytic Infundibulo-neurohypophysitis. J Clin Endocrinol Metab. 2015; 100(7): E946-E954, doi: 10.1210/jc.2014-4209, indexed in Pubmed: 25919460.

89. Faje A. Hypophysitis: Evaluation and Management. Clin Diabetes Endocrinol. 2016; 2(1): 15, doi: 10.1186/s40842-016-0034-8, indexed in Pubmed: 28702249.

90. De Bellis A, Sinisi AA, Pane E, et al. Italian Autoimmune Hypophysitis Network Group. Involvement of hypothalamus autoimmunity in patients with autoimmune hypopituitarism: role of antibodies to hypothalamic cells. J Clin Endocrinol Metab. 2012; 97(10): 3684-3690, doi: 10.1210/jc.2012-2269, indexed in Pubmed: 22855340.

91. De Bellis A, Colao A, Di Salle F, et al. A longitudinal study of vasopressin cell antibodies, posterior pituitary function, and magnetic resonance imaging evaluations in subclinical autoimmune central diabetes insipidus. J Clin Endocrinol Metab. 1999; 84(9): 3047-3051, doi: 10.1210/jcem.84.9.5945, indexed in Pubmed: 10487663.

92. Thapar K, Kohata T, Laws ER. Parasellar lesions other than pituitary adenomas. In: Powell MP, Lightman SL. ed. Management of Pituitary Tumor. The Clinician's Practical Guide. 2nd ed. Humana Press, New Jersey 2003: 231-286.

93. Kelestimur F. Sheehan's Syndrome. Pituitary. 2003; 6(4): 181-188, doi: 10.1023/b:pitu.0000023425.20854.8e, indexed in Pubmed: 15237929.

94. De Bellis A, Kelestimur F, Sinisi AA, et al. Anti-hypothalamus and anti-pituitary antibodies may contribute to perpetuate the hypopituitarism in patients with Sheehan's syndrome. Eur J Endocrinol. 2008, 158(2): 147-152, doi: 10.1530/EJE-07-0647, indexed in Pubmed: 18230820.

95. Charmandari E, Nicolaides NC, Chrousos GP. Adrenal insufficiency. Lancet. 2014; 383(9935): 2152-2167, doi: 10.1016/S0140-6736(13)61684-0, indexed in Pubmed: 24503135.

96. Hannoush ZC, Weiss RE. Hypopituitarism: emergencies. Endotext [Internet]. South Dartmouth 2018. https://www.ncbi.nlm.nih. gov/books/NBK279063/.

97. Khare S, Jagtap VS, Budyal SR, et al. Primary (autoimmune) hypophysitis: a single centre experience. Pituitary. 2015; 18(1): 16-22, doi: 10.1007/s11102-013-0550-9, indexed in Pubmed: 24375060.

98. Huguet I, Clayton R. Pituitary-hypothalamic tumor syndromes: adults. Endotext [Internet]. South Dartmouth 2015. https://www.ncbi. nlm.nih.gov/books/NBK278946/.

99. Caputo C, Bazargan A, McKelvie PA, et al. Hypophysitis due to IgG4-related disease responding to treatment with azathioprine: an alternative to corticosteroid therapy. Pituitary. 2014; 17(3): 251-256, doi: 10.1007/s11102-013-0498-9, indexed in Pubmed: 23794123.

100. Schreckinger M, Francis T, Rajah G, et al. Novel strategy to treat a case of recurrent lymphocytic hypophysitis using rituximab. J Neurosurg. 2012; 116(6): 1318-1323, doi: 10.3171/2012.2.JNS111456, indexed in Pubmed: 22443503

101. Krysiak R, Samborek M, Stojko R. Anti-inflammatory effects of bromocriptine in a patient with autoimmune polyglandular syndrome type 2. Neuro Endocrinol Lett. 2014; 35(3): 179-182, indexed in Pubmed: 24977964.

102. Hypophystis Research Centre at Johns Hopkins Medical Institutions. http://pathology.jhu.edu/hypophysitis/.

103. Lupi I, Manetti L, Raffaelli V, et al. Diagnosis and treatment of autoimmune hypophysitis: a short review. J Endocrinol Invest. 2011; 34(8): e245-e252, doi: 10.3275/7863, indexed in Pubmed: 21750396.

104. Lupi I, Cosottini M, Caturegli P, et al. Diabetes insipidus is an unfavorable prognostic factor for response to glucocorticoids in patients with autoimmune hypophysitis. Eur J Endocrinol. 2017; 177(2): 127-135, doi: 10.1530/EJE-17-0123, indexed in Pubmed: 28626085

105. Corsello SM, Barnabei A, Marchetti P, et al. Endocrine side effects induced by immune checkpoint inhibitors. J Clin Endocrinol Metab. 2013; 98(4): 1361-1375, doi: 10.1210/jc.2012-4075, indexed in Pubmed: 23471977.

106. Hodi FS, O'Day SJ, McDermott DF, et al. Improved survival with ipilimumab in patients with metastatic melanoma. N Engl J Med. 2010; 363(8): 711-723, doi: 10.1056/NEJMoa1003466, indexed in Pubmed: 20525992.

107. Król A, Gawlik T, Jarzab B. Endocrine complications of cancer immunotherapy. Endokrynol Pol. 2018; 69(6): 722-733, doi: 10.5603/EP.a2018.0073, indexed in Pubmed: 30618030.

108. Min Le, Hodi FS, Giobbie-Hurder A, et al. Systemic high-dose corticosteroid treatment does not improve the outcome of ipilimumab-related hypophysitis: a retrospective cohort study. Clin Cancer Res. 2015; 21(4): 749-755, doi: 10.1158/1078-0432.CCR-14-2353, indexed in Pubmed: 25538262.

109. Faje AT, Sullivan R, Lawrence D, et al. Ipilimumab-induced hypophysitis: a detailed longitudinal analysis in a large cohort of patients with metastatic melanoma. J Clin Endocrinol Metab. 2014; 99(11): 4078-4085, doi: 10.1210/jc.2014-2306, indexed in Pubmed: 25078147.

110. Iwama S, De Remigis A, Callahan MK, et al. Pituitary expression of CTLA-4 mediates hypophysitis secondary to administration of CTLA-4 blocking antibody. Sci Transl Med. 2014; 6(230): 230ra45, doi: 10.1126/scitranslmed.3008002, indexed in Pubmed: 24695685.

111. Romano E, Kusio-Kobialka M, Foukas PG, et al. Ipilimumab-dependent cell-mediated cytotoxicity of regulatory $\mathrm{T}$ cells ex vivo by nonclassical monocytes in melanoma patients. Proc Natl Acad Sci USA. 2015; 112(19): 6140-6145, doi: 10.1073/pnas.1417320112, indexed in Pubmed: 25918390

112. Laurent S, Queirolo P, Boero S, et al. The engagement of CTLA-4 on primary melanoma cell lines induces antibody-dependent cellular cytotoxicity and TNF- production. J Transl Med. 2013; 11: 108, doi: 10.1186/1479-5876-11-108, indexed in Pubmed: 23634660.

113. De Sousa SMC, Sheriff N, Tran $\mathrm{CH}$, et al. Fall in thyroid stimulating hormone (TSH) may be an early marker of ipilimumab-induced hypophysitis. Pituitary. 2018; 21(3): 274-282, doi: 10.1007/s11102-018-0866-6, indexed in Pubmed: 29380110.

114. Chodakiewitz Y, Brown S, Boxerman JL, et al. Ipilimumab treatment associated pituitary hypophysitis: clinical presentation and imaging 
diagnosis. Clin Neurol Neurosurg. 2014; 125: 125-130, doi: 10.1016/j clineuro.2014.06.011, indexed in Pubmed: 25127260.

115. Faje A. Immunotherapy and hypophysitis: clinical presentation, treatment, and biologic insights. Pituitary. 2016; 19(1): 82-92, doi: 10.1007/s11102-015-0671-4, indexed in Pubmed: 26186958.

116. Scott ES, Long GV, Guminski A, et al. The spectrum, incidence, kinetics and management of endocrinopathies with immune checkpoint inhibitors for metastatic melanoma. Eur J Endocrinol. 2018; 178(2): 173-180, doi: 10.1530/EJE-17-0810, indexed in Pubmed: 29187509.

117. Caturegli P, Di Dalmazi G, Lombardi M, et al. Hypophysitis Secondary to Cytotoxic T-Lymphocyte-Associated Protein 4 Blockade: Insights into Pathogenesis from an Autopsy Series. Am J Pathol 2016; 186(12): 3225-3235, doi: 10.1016/j.ajpath.2016.08.020, indexed in Pubmed: 27750046.
118. Tanriverdi F, De Bellis A, Bizzarro A, et al. Antipituitary antibodies after traumatic brain injury: is head trauma-induced pituitary dysfunction associated with autoimmunity? Eur J Endocrinol. 2008; 159(1): 7-13, doi: 10.1530/EJE-08-0050, indexed in Pubmed: 18463108.

119. Tanriverdi F, Unluhizarci K, Kelestrimur F. Persistent neuroinflammation may be involved in the pathogenesis of traumatic brain injury (TBI) induced hypopituitarism: potential genetic and autoimmune factors. Neurotrauma. 2010; 27(2): 301-302, doi: 10.1089/neu.2009.1102, indexed in Pubmed: 19831821.

120. Tanriverdi $F$, De Bellis A, Ulutabanca $H$, et al. A five year prospective investigation of anterior pituitary function after traumatic brain injury: is hypopituitarism long-term after head trauma associated with autoimmunity? J Neurotrauma. 2013; 30(16): 1426-1433, doi: 10.1089/neu.2012.2752, indexed in Pubmed: 23470214 